\title{
Comparison of Fenton and Photo-Fenton Processes for Removal of Linear Alkyle Benzene Sulfonate (Las) from Aqueous Solutions
}

\author{
Mohammad Bagher Miranzadeh ${ }^{1}$, Rouhullah Zarjam², Rouhullah Dehghani', \\ Mohsen Haghighi², Hakime Zamani Badi ${ }^{3}$, Milad Ahmadi Marzaleh", \\ Ashraf Mazaheri Tehrani ${ }^{5 *}$
}

\begin{abstract}
${ }^{1}$ Department of Environmental Health Engineering, Faculty of Health and Social Determinants of Health (SDH) Research Center, Kashan University of Medical Science, Iran

${ }^{2}$ Department of Environmental Health Engineering, Faculty of Health, Kashan University of Medical Science, Iran

${ }^{3}$ Student Research Committee, Sabzevar University of Medical Sciences, Sabzevar, Iran

${ }^{4}$ M.Sc Student of Management of Health, Safety and Environment, Faculty of Health, safety and environment, Shahid Beheshti University of Medical Science, Iran.

${ }^{5}$ Social Determinants in Health Promotion Research Center, Hormozgan University of Medical Sciences,
\end{abstract} Bandar Abbas, Iran

Received: 12 November 2015

Accepted: 16 February 2016

\begin{abstract}
The aim of our study was to investigate the effectiveness of Fenton and photo-Fenton processes for removing anionic surfactants from aqueous solutions. The study was conducted using $200 \mathrm{mgL}^{-1}$ linear alkyl benzene Sulfonate (LAS) as a model of anionic surfactants. This study revealed that the mean removal efficiency of LAS in Fenton and photo-Fenton at 20 minutes reaction time at $100 \mathrm{mgL}^{-1}$ constant concentration of hydrogen peroxide and $20 \mathrm{mgL}^{-1}$ ferrous Iron were 20.16 and $22.47 \%$, respectively. Meanwhile, LAS removal efficiency (at 80 minutes reaction time for constant concentration of $800 \mathrm{mgL}^{-1}$ hydrogen peroxide and $120 \mathrm{mgL}^{-1}$ ferrous ion) were 69.38 and $86.66 \%$, respectively, which is consistent with the significant increase in the rate of LAS removal efficiency with reaction time $(\mathrm{P}<0.05)$. In conclusion, anionic surfactants removal was significantly correlated with reaction time by both methods, but showed less dependence on $\mathrm{H}_{2} \mathrm{O}_{2}$ and $\mathrm{Fe}^{2+}$ concentrations.
\end{abstract}

Keywords: anionic surfactants, detergent, Fenton process, photo-Fenton process

*e-mail: mazaheri452@gmail.com 


\section{Introduction}

Surfactants are the main ingredients of synthetic detergents [1]. They are widely used in soap, toothpaste, cleaning detergents, and shampoo $[2,3]$. They also have numerous industrial applications in cosmetic and medicinal products, textiles, foodstuffs, paper, oil recovery, paints, polymers, pesticides, and mining [2, 4].

According to their hydrophilic properties, surfactants are categorized into four classes (cationic, anionic, amphoteric, and non-ionic) [5, 6]. Ionic surfactants (anionic and cationic surfactants) constitute approximately two-thirds of all surfactants, and anionics constitute more than $90 \%$ of all Ionics [7]. One estimate of worldwide surfactant production is 13 million tons per year [8]. Also, statistics from the Council of European Surfactants Producers place the total quantity of surfactants (without soaps) consumed in Western Europe at more than 3 million tons [9].

Surfactants can be partly biodegraded under aerobic conditions in wastewater, but they are rarely biodegraded under anaerobic conditions [7, 10-12]. Consequently, they are discharged to surface water and groundwater through household and industrial wastewaters [13]. They also cause foam in rivers and effluent treatment plants and reduce water quality, and also cause short- and longterm damage to the environment [14-16]. Surfactants are harmful for fish and human beings [14] - for instance LAS in low concentrations (i.e., $1 \mathrm{mgL}^{-1}$ can poison aquatic organisms) [17]. LAS poisoning may increase proportionally to total carbon content of the alkyl chain [2]. It has been reported that LAS at concentrations of less than $10 \mathrm{mgL}^{-1}$ is biodegradable under aerobic activated sludge treatment.

Mehrvar et al. reported that LAS biodegradability depends on its concentration. LAS solutions with 100 $\mathrm{mgL}^{-1}$ concentration are non-biodegradable and have inhibitory effects on microorganisms [12]. Therefore, due to their resistance against biodegradation, they can accumulate in aqueous environments and could threaten the health of aquatic organisms, animals, and human beings $[8,18]$. The removal efficiency of surfactants from aqueous environments depends on the method of treatment employed [18]. Various procedures are employed for removing or destroying surfactants, including an anaerobic fluidized bed reactor (FBR) [19], chemical or electro-chemical oxidation, membrane technology, chemical precipitation, and photo catalytic degradation $[6,17,20-22]$. However, the limitations of biological procedures and difficulties in using other technologies (such as membranes) or adsorbing procedures challenge us to develop and employ new methodologies to deal with this issue [5]. Thus, advanced oxidation processes (AOPs) are recommended for pretreating wastewater or tertiary treatment when wastewater compounds have a high chemical stability and/or low biodegradability. AOPs come in numerous types, including oxidation with ozone [23], Fenton $\left(\mathrm{Fe}^{2+} / \mathrm{H}_{2} \mathrm{O}_{2}\right)$, electro-Fenton [24], photoFenton $\left(\mathrm{Fe}^{2+} / \mathrm{H}_{2} \mathrm{O}_{2} / \mathrm{UV}\right), \mathrm{UV} / \mathrm{H}_{2} \mathrm{O}_{2}$, etc. [25-28].
Fenton and photo-Fenton reactions are AOPs where oxidant species are generated from hydrogen peroxide and $\mathrm{Fe}^{2+} / \mathrm{Fe}^{3+}$ as a catalyst [29]. In a Fenton reaction ferrous salts react with hydrogen peroxide and generate the hydroxyl radicals according to (1):

$$
\mathrm{Fe}^{2+}+\mathrm{H}_{2} \mathrm{O}_{2} \rightarrow \mathrm{Fe}^{3+}+\mathrm{HO}+\mathrm{HO}^{-}
$$

Then $\mathrm{Fe}^{3+}$ can be reduced by reaction with $\mathrm{H}_{2} \mathrm{O}_{2}$ to form ferrous ion again with an additional amount of hydroxyl radicals. This second process is called a "Fenton-like process." It is slower than the Fenton reaction and allows $\mathrm{Fe}^{2+}$ regeneration to appear as a catalyst according to $(2-4)$ :

$$
\begin{gathered}
\mathrm{Fe}^{3+}+\mathrm{H}_{2} \mathrm{O}_{2} \leftrightarrow \mathrm{FeOOH}^{2+}+\mathrm{H}^{+} \\
\mathrm{FeOOH}^{2+} \rightarrow \mathrm{HO}_{2}^{\cdot}+\mathrm{Fe}^{2+} \\
\mathrm{Fe}^{3+}+\mathrm{HO}_{2}^{\cdot} \rightarrow \mathrm{Fe}^{2+}+\mathrm{O}_{2}+\mathrm{H}^{+}
\end{gathered}
$$

The rate of contaminant degradation can be considerably increased due to photochemical reaction in the photo-Fenton process. In this case, the regeneration of $\mathrm{Fe}^{2+}$, with additional production of Hydroxyl radicals, is followed by the photo reduction process according to (5-6).

$$
\begin{gathered}
\mathrm{Fe}^{3+}+\mathrm{H}_{2} \mathrm{O} \rightarrow \mathrm{FeOH}^{2+}+\mathrm{H}^{+} \\
\mathrm{FeOH}^{2+}+\mathrm{h} v \rightarrow \mathrm{Fe}^{2+}+\mathrm{HO} \cdot \lambda<410 \mathrm{~nm}
\end{gathered}
$$

Although several studies have been conducted on the treatment of surfactant wastewater using various methods such as combined Fenton oxidation and aerobic biological, ultrasonic, simultaneous use of ozone and powdered activated carbon, nano flocculation, photo catalysis, iron species as heterogeneous catalysts, $\mathrm{UV} / \mathrm{H}_{2} \mathrm{O}_{2}$ chemical oxidation, Fenton-like reaction over zerovalent iron-based catalyst, and bioremediation [30-37].

Moreover, literature shows that Fenton has been utilized to treat azo dyes, phenols, nitrobenzene, COD, herbicides, and Di-(2-Ethylhexyl) phthalate (DEHP), as well as to reduce linear alkylbenzene sulfonate (LAS) in wastewater [38-43]. The photo-Fenton process also has been utilized to treat inorganic and organic components in synthetic or real aqueous solutions such as LAS, COD, Metoprolol, TOC, and pesticides [39, 42, 44-47].

Abu Hassan et al. showed that the initial concentration of LAS increases its degradation [48]. Also, Ono et al. on non-ionic surfactant degradation with anionic and cationic surfactant compound performed by photo-Fenton process found that UV light is effective in forming $\mathrm{OH}$ radical, resulting in accelerating the photo-Fenton reaction [49].

Based on literature review, other research has not compared the Fenton and photo-Fenton processes for removal of LAS. Thus the main objective of our study was to compare their efficiency for removal of LAS 
from synthetic wastewater under similar conditions and investigate the effects of iron concentration, $\mathrm{H}_{2} \mathrm{O}_{2}$ dose, and reaction time on LAS removal.

\section{Materials and Methods}

\section{Chemicals}

The surfactant used in this study contained $88 \%$ sodium dodecylbenzenesulfonate (LAS) provided by ACROS ORGANIC. SDBS was used as anionic surfactant (family: LAS) for performing experiments. Other chemicals such as $\mathrm{H}_{2} \mathrm{SO}_{4}, \mathrm{FeSO}_{4} 7 \mathrm{H}_{2} \mathrm{O}, \mathrm{NaOH}$, hydrogen peroxide $(30 \% \mathrm{v}$ : $\mathrm{v}$ solution $), \mathrm{CHCl}_{3}$, $\mathrm{NaH}_{2} \mathrm{PO}_{4} \cdot \mathrm{H}_{2} \mathrm{O}$, and methylene blue were supplied by Merck Co.

\section{Experimental Setup}

\section{Fenton Process}

Experiments were performed at room temperature in a $2 \mathrm{~L}$ glass cylindrical reactor that was protected from incident light by aluminum foil. The reactor was equipped with a magnetic stirrer to completely mix the reagents $\left(\mathrm{H}_{2} \mathrm{O}_{2}\right.$ and $\mathrm{Fe}^{2+}$ ion).

\section{Photo-Fenton Process}

As shown in Fig. 1, the photo-Fenton process was carried out in a $2 \mathrm{~L}$ glass reactor equipped with an external light irradiation-type photo reactor. The photo reactor was mounted on a magnetic stirrer and complete mixing of the reagents $\left(\mathrm{H}_{2} \mathrm{O}_{2}\right.$ and $\mathrm{Fe}^{2+}$ ion) was achieved by magnetic stirring. The UV light irradiation sources were four 15-Watt UV-C lamps (Osram G15T8) having peak radiation at $254 \mathrm{~nm}$ wavelength. The distance between the photo reactor surface and the lamps (which were parallel to the photo reactor axis) was $3 \mathrm{~cm}$.

\section{Experimental Procedure}

The laboratory unit was filled separately with $1 \mathrm{~L}$ of synthetic wastewater. The initial concentration of the LAS solutions in units was $200 \mathrm{mgL}^{-1}$. Since optimum $\mathrm{pH}$ of about 3 had been observed by the previous researchers for the Fenton and photo-Fenton processes, the $\mathrm{pH}$ of the solution was maintained constant at $\mathrm{pH} 3.0$ by the addition of $\mathrm{NaOH}$ or $\mathrm{HCl}$. For runs using the Fenton and the photo-Fenton processes, a given weight of iron salt was added. The iron salt was mixed very well with the wastewater before the addition of a given volume of hydrogen peroxide. For the photo-Fenton process, the time at which the ultraviolet lamp was turned on was considered time zero, or the beginning of the experiment, which was taking place simultaneously with the addition of hydrogen peroxide. At selected time intervals, supernatants of the solution were withdrawn and the reaction stopped by the addition of aqueous $\mathrm{NaOH}$ (final $\mathrm{pH}$ of ca. 12) to precipitate iron oxides.

\section{Analytical Determinations}

The $\mathrm{pH}$ of the solution was measured using a TS-TECHNOLOGY PH262 $\mathrm{pH}$ meter. LAS was measured

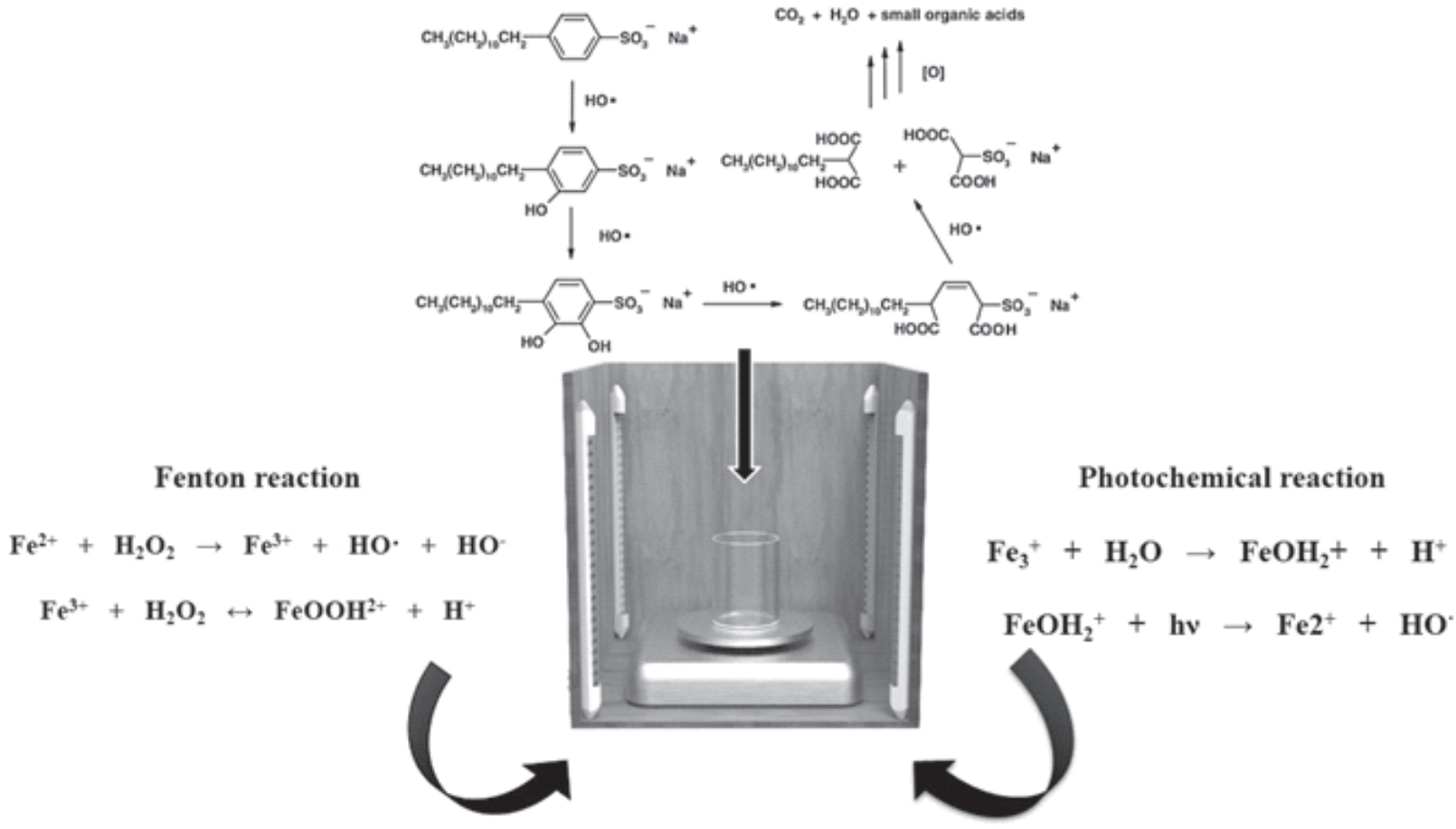

Fig.1. Schematic of pilot-plant of photo-Fenton reactor in our study. 
Table 1. The mean and standard deviation of remaining anionic surfactant (LAS) according to various parameters in Fenton and photoFenton processes.

\begin{tabular}{|c|c|c|c|c|}
\hline P value & $\begin{array}{c}\text { Photo-Fenton } \\
\mathrm{X} \pm \text { S.D }\end{array}$ & $\begin{array}{l}\text { Fenton } \\
\mathrm{X} \pm \mathrm{S} . \mathrm{D}\end{array}$ & Method & Variable \\
\hline 0.136 & $148.37 \pm 28.45$ & $155.64 \pm 24.5$ & 100 & \multirow{5}{*}{$\mathrm{H}_{2} \mathrm{O}_{2}(\mathrm{mg} / \mathrm{l})$} \\
\hline 0.121 & $130.28 \pm 43.72$ & $141.57 \pm 34.88$ & 300 & \\
\hline 0.065 & $122.14 \pm 46.03$ & $136.55 \pm 38.2$ & 600 & \\
\hline 0.042 & $113.61 \pm 51.8$ & $131.25 \pm 41.6$ & 800 & \\
\hline 0.001 & $128.59 \pm 44.97$ & $141.25 \pm 36.31$ & total & \\
\hline 0.059 & $143.22 \pm 33.32$ & $153.7 \pm 26.43$ & 20 & \multirow{5}{*}{$\mathrm{Fe}^{2+}(\mathrm{mg} / \mathrm{l})$} \\
\hline 0.016 & $131.72 \pm 42.31$ & $147.96 \pm 29.24$ & 50 & \\
\hline 0.125 & $122.52 \pm 47.48$ & $134.85 \pm 39.67$ & 80 & \\
\hline 0.182 & $116.94 \pm 54.34$ & $128.5 \pm 42.47$ & 120 & \\
\hline 0.001 & $128.59 \pm 44.97$ & $141.25 \pm 36.31$ & total & \\
\hline- & 200 & 200 & 0 & \multirow{6}{*}{ Time(min) } \\
\hline 0.000 & $135.4 \pm 14.53$ & $145.47 \pm 10.63$ & 20 & \\
\hline 0.001 & $122.25 \pm 18.7$ & $134.32 \pm 14.59$ & 40 & \\
\hline 0.000 & $103.28 \pm 22.14$ & $18 / 120 \pm 69 / 19$ & 60 & \\
\hline 0.000 & $82.05 \pm 32.75$ & $106.29 \pm 26.42$ & 80 & \\
\hline 0.001 & $128.59 \pm 44.97$ & $141.25 \pm 36.31$ & total & \\
\hline
\end{tabular}

using methylene blue active substance (MBAS) on the basis of the 5540.C method in the Standard Methods book (Carlos et al., 2008). The experiments were based on the transfer of MBAS from an aqueous solution into an immiscible phase containing anionic surfactant. This transfer was possible by ion pair formation when methylene

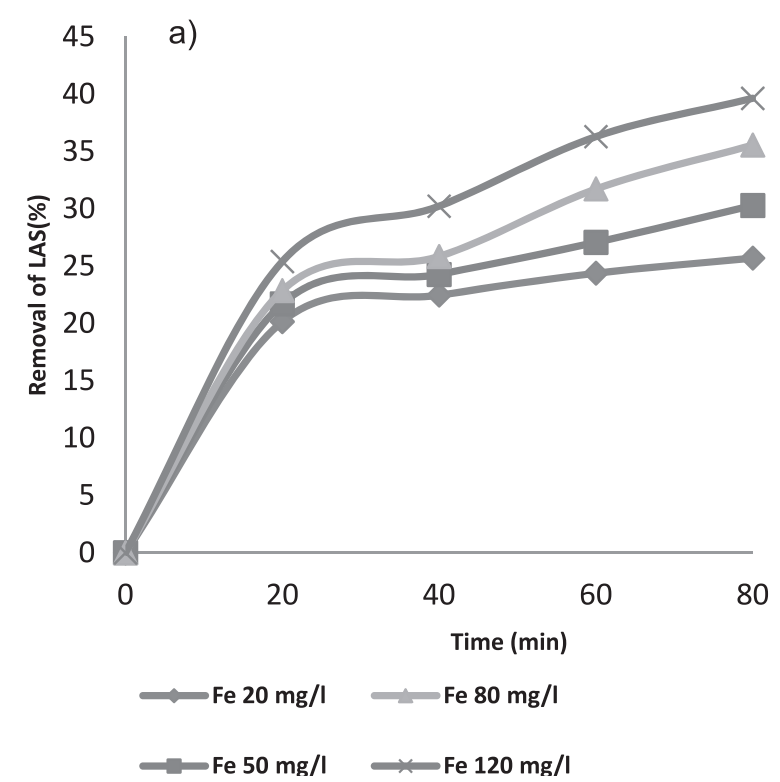

Fig. 2a). Effect of reaction time on Fenton process for the degradation LAS (conditions: initial LAS degradation, $200 \mathrm{mgL}^{-1}$; initial PH, 3; $\mathrm{H}_{2} \mathrm{O}_{2}$ concentration; $100 \mathrm{mgL}^{-1}$ ). blue, a cationic dye, reacts with anionic surfactants. The MBAS method comprises three successive extractions from aqueous medium containing excess methylene blue into chloroform $\left(\mathrm{CHCl}_{3}\right)$, followed by an aqueous backwash and measurement of the blue

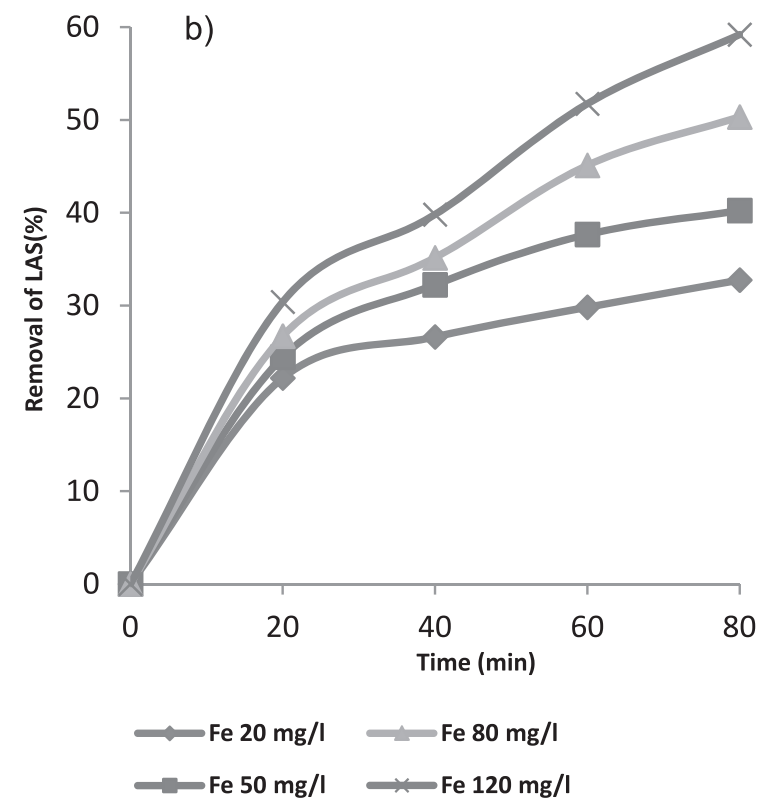

Fig. 2b). Effect of reaction time on Fenton process for the degradation LAS (conditions: initial LAS degradation, $200 \mathrm{mgL}^{-1}$; initial $\mathrm{PH}, 3 ; \mathrm{H}_{2} \mathrm{O}_{2}$ concentration; $300 \mathrm{mgL}^{-1}$ ). 
color in the $\mathrm{CHCl}_{3}$ by spectrophotometer at $652 \mathrm{~nm}$. Excess methylene blue was read by an HACH-DR 2010 spectrophotometer.

\section{Statistical Methods}

After collecting data concerning mean and standard deviation, the eliminated LAS according to reaction time

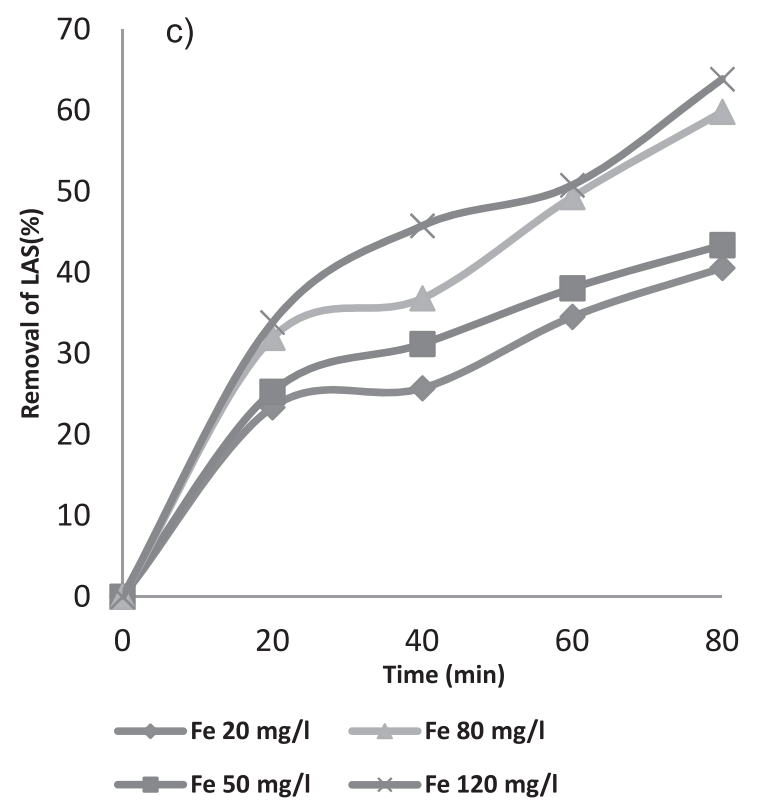

Fig. 2c). Effect of reaction time on Fenton process for the degradation LAS (conditions: initial LAS degradation, $200 \mathrm{mgL}^{-1}$; initial $\mathrm{PH}, 3 ; \mathrm{H}_{2} \mathrm{O}_{2}$ concentration; $600 \mathrm{mgL}^{-1}$ ).

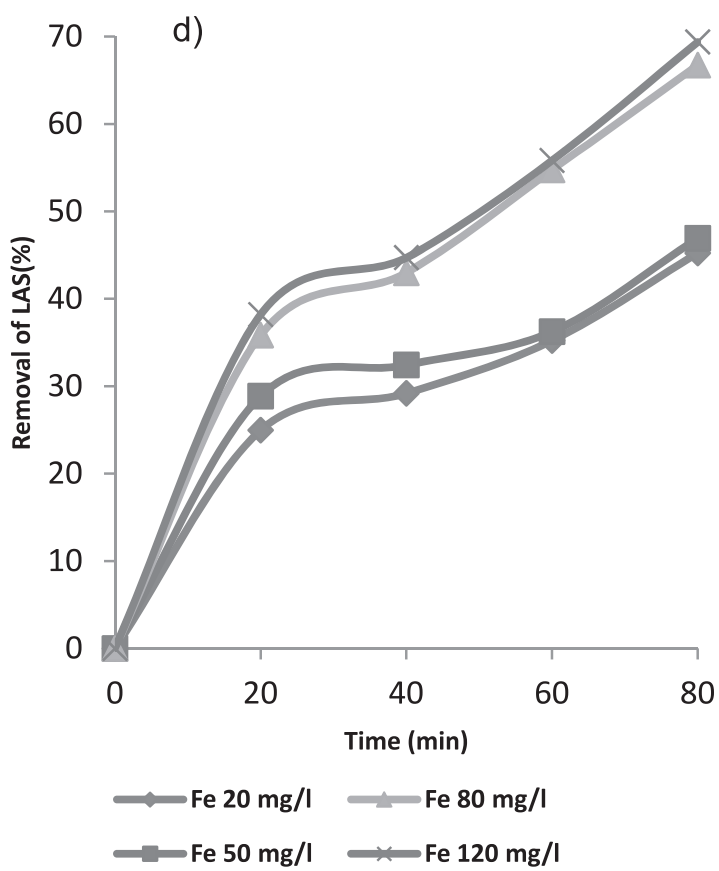

Fig. 2d). Effect of reaction time on Fenton process for the degradation LAS (conditions: initial LAS degradation, $200 \mathrm{mgL}^{-1}$; initial PH, 3; $\mathrm{H}_{2} \mathrm{O}_{2}$ concentration; $800 \mathrm{mgL}^{-1}$ ). variables, $\mathrm{Fe}^{2+}$ ion and $\mathrm{H}_{2} \mathrm{O}_{2}$ concentrations were measured. The process capacity of Fenton and photo-Fenton in biodegrading LAS was measured by the presence of changeable concentrations of $\mathrm{H}_{2} \mathrm{O}_{2}$ and $\mathrm{Fe}^{2+}$ using two-way ANOVA, and reaction time using repeated measurement analysis. Then the post-hoc Tukey test was used.

\section{Results}

Table 1 shows the results of the mean and standard deviation of remaining anionic surfactant based on reaction time, concentration of hydrogen peroxide, and concentration of $\mathrm{Fe}^{2+}$ for both Fenton and photo-Fenton processes. As shown in this table, it is obvious that minimum and maximum remaining concentrations of LAS occur at 80 and 20 Minutes reaction time, respectively (without consideration of the blank sample).

The removal percentage of LAS for the Fenton process, with constant concentration of $100 \mathrm{mgL}^{-1}$ hydrogen peroxide and $20 \mathrm{mgL}^{-1} \mathrm{Fe}^{2+}$ based on reaction time of 20 minutes, is shown in Figs 2(a, b, c, d), where the minimum removal was $20.16 \%$, whereas in constant concentration of $800 \mathrm{mgL}^{-1}$ hydrogen peroxide and $120 \mathrm{mgL}^{-1} \mathrm{Fe}^{2+}$ with reaction time at 80 minutes it was $69.38 \%$, which shows the maximum removal percentage.

Also, on the photo-Fenton process Figs 3(a, b, c, d), the removal percentage of LAS with constant concentration of $100 \mathrm{mgL}^{-1}$ hydrogen peroxide and $20 \mathrm{mgL}^{-1} \mathrm{Fe}^{2+}$ based on reaction time of 20 minutes was $22.47 \%$, which shows the least removal percentage, whereas in constant concentration of $800 \mathrm{mgL}^{-1}$ hydrogen peroxide and $120 \mathrm{mgL}^{-1} \mathrm{Fe}^{2+}$ with reaction time at 80 minutes it was $86.66 \%$, which shows the highest removal percentage. In both photo-Fenton and Fenton processes, the removal rate of LAS increased with increasing concentrations of $\mathrm{H}_{2} \mathrm{O}_{2}$ and the $\mathrm{Fe}^{2+}$ ion, and reaction time.

As shown in Table 2, the effects of reaction time by itself and other counter-effects are significantly meaningful $(\mathrm{P}$ value $<0.05)$, but counter-effects of time, the process, $\mathrm{Fe}^{2+}$ concentration, and $\mathrm{H}_{2} \mathrm{O}_{2}$ concentration were not significantly meaningful $(\mathrm{P}$ value $=0.308)$.

\section{Discussion}

Previous studies have shown that Fenton efficiency depends on sample characteristics, $\mathrm{PH}, \mathrm{Fe}^{2+}$ concentration, $\mathrm{H}_{2} \mathrm{O}_{2}$ dose, and reaction time. In our study, sample concentration and $\mathrm{PH}$ were constant, but $\mathrm{Fe}^{2+}$ concentration and $\mathrm{H}_{2} \mathrm{O}_{2}$ dose varied.

\section{The Effect of Hydrogen Peroxide}

Regarding Figs 2(a, b, c, d) and 3(a, b, c, d), it is indicated that with increasing the initial concentration of hydrogen peroxide, LAS removal and degradation rates mount. For example, the removal rate in a constant concentration of photo-Fenton process with $80 \mathrm{mgL}^{-1} \mathrm{Fe}^{2+}$ 
Table 2. References of differences of LAS removal by using repeated measurements model on the presence of time factor and its mutual effect on the presence of other factors.

\begin{tabular}{|c|c|c|c|c|c|}
\hline Source & Type III sum of squares & Df & Mean square & $\mathrm{F}$ & $\mathrm{P}_{\text {value }}$ \\
\hline Time & 29149.2 & 1.15 & 25385.07 & 1637.67 & 0.000 \\
\hline Time* method & 715.83 & 1.15 & 623.39 & 40.218 & 0.000 \\
\hline Time $* \mathrm{H}_{2} \mathrm{O}_{2}$ dose & 2148.28 & 3.445 & 623.62 & 40.232 & 0.000 \\
\hline Time $* \mathrm{Fe}^{2+}$ dose & 1259.47 & 3.445 & 365.61 & 23.587 & 0.000 \\
\hline Time*method $* \mathrm{H}_{2} \mathrm{O}_{2}$ dose & 179.31 & 3.445 & 52.05 & 3.358 & 0.018 \\
\hline Time*method*Fe ${ }^{2+}$ dose & 170.42 & 3.445 & 49.47 & 3.192 & 0.023 \\
\hline Time $* \mathrm{H}_{2} \mathrm{O}_{2}$ dose $* \mathrm{Fe}^{2+}$ dose & 380.45 & 10.335 & 36.81 & 2.375 & 0.016 \\
\hline Time*method $* \mathrm{H}_{2} \mathrm{O}_{2}$ dose $* \mathrm{Fe}^{2+}$ dose & 191.19 & 10.335 & 18.5 & 1.194 & 0.308 \\
\hline
\end{tabular}

and 60 minutes and in $100,300,600$, and $800 \mathrm{mgL}^{-1}$ of $\mathrm{H}_{2} \mathrm{O}_{2}$ is $36.08,50.41,56.79$, and $63.36 \%$, respectively, which is likely due to the rate of $\mathrm{OH}$ radical production. According to previous studies, increasing the initial concentration of $\mathrm{H}_{2} \mathrm{O}_{2}$ increases the rate of $\mathrm{OH}$ radical production. Previous studies also have found that increasing $\mathrm{OH}$ radical production is done due to certain concentrations of $\mathrm{H}_{2} \mathrm{O}_{2}$, and if $\mathrm{H}_{2} \mathrm{O}_{2}$ is added to the process it causes limitation and removal of the procedure [50-53].

\section{The Effect of $\mathrm{Fe}^{2+}$ Concentration}

The obtained results from Figs 2(a, b, c, d) and 3(a, $\mathrm{b}, \mathrm{c}, \mathrm{d})$ indicate that increasing the $\mathrm{Fe}^{2+}$ concentration causes the LAS removal and degradation rates to increase and, therefore, the rate of $\mathrm{OH}$ radical increases, too. For instance, in the Fenton process for constant concentration

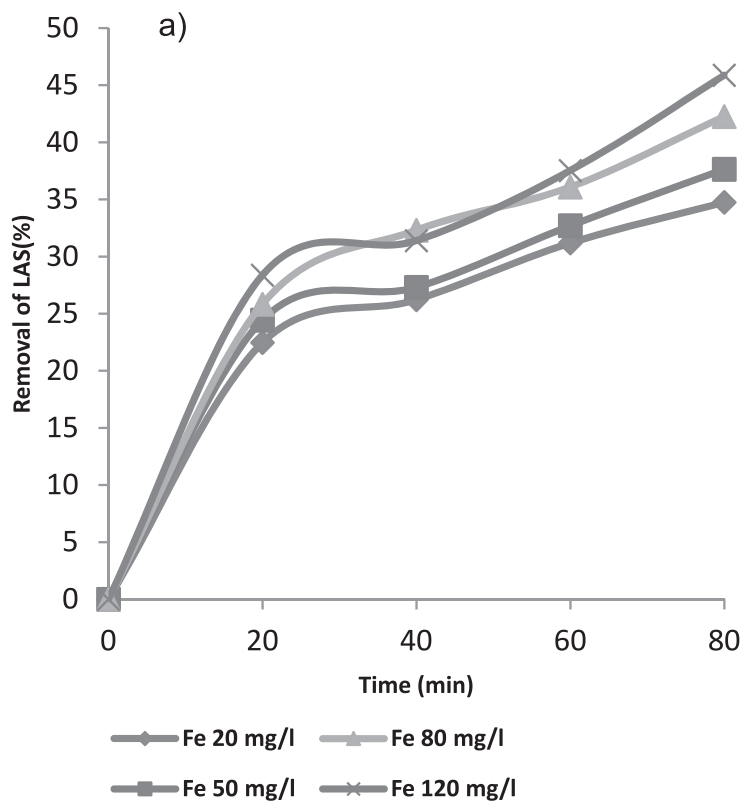

Fig. 3a). Effect of reaction time on photo-Fenton process for the degradation LAS (conditions: initial LAS degradation, $200 \mathrm{mgL}^{-1}$; initial $\mathrm{PH}, 3 ; \mathrm{H}_{2} \mathrm{O}_{2}$ concentration; $100 \mathrm{mgL}^{-1}$ ). of $600 \mathrm{mgL}^{-1} \mathrm{H}_{2} \mathrm{O}_{2}$ and 80 minutes, the removal rate of $\mathrm{Fe}^{2+}$ concentration for $20,50,80$, and $120 \mathrm{mgL}^{-1}$ was $40.59,43.4,59.85$, and $63.88 \%$, respectively, which is consistent with our previous study [53-55].

Thus $\mathrm{Fe}^{2+}$ increases oxidation rate by producing $\mathrm{OH}$ radicals $\left(\mathrm{OH}^{*}\right)$ according to (1).

On the other hand, a high dose of $\mathrm{Fe}^{2+}$ is not practically advised, but a low dosage is advised in industrial applications since its highly used dosage demands higher costs and later treatment may be needed. It also causes more sludge which, in turn, increases removal costs $[51,55]$.

Although we could mount oxidation rates by increasing $\mathrm{Fe}^{2+}$ in our study, it has been proven in some studies that a higher dosage of $\mathrm{Fe}^{2+}$ can cause $\mathrm{OH}$ radicals $\left(\mathrm{OH}^{\circ}\right)$ recombination. In this case, $\mathrm{Fe}^{2+}$ reacts as a scavenger [51, $52,54,55]$.

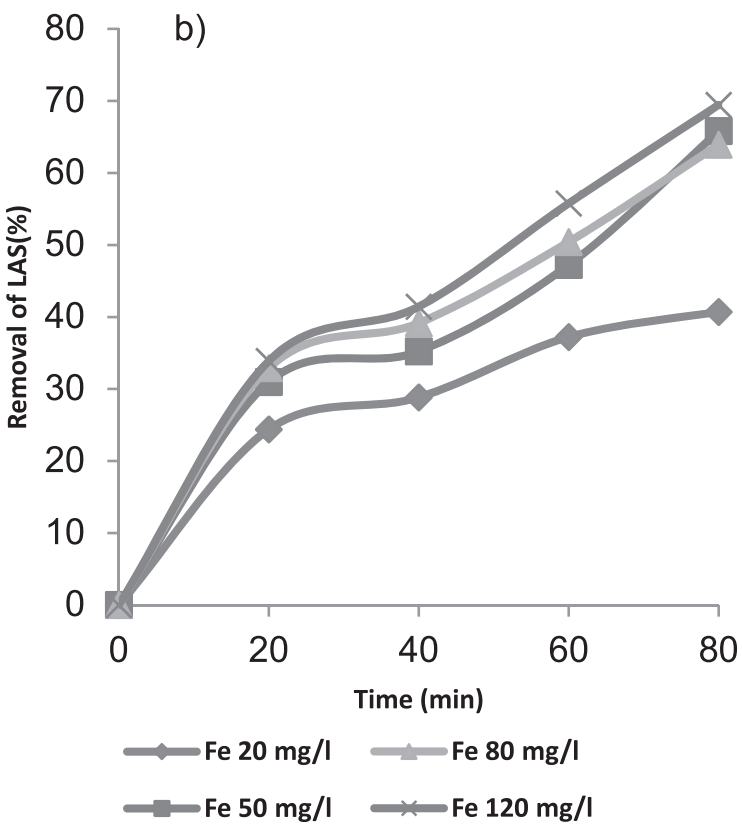

Fig. 3b). Effect of reaction time on photo-Fenton process for the degradation LAS (conditions: initial LAS degradation, $200 \mathrm{mgL}^{-1}$; initial $\mathrm{PH}, 3 ; \mathrm{H}_{2} \mathrm{O}_{2}$ concentration; 300 $\mathrm{mLL}^{-1}$ ). 
In addition, overtly increasing $\mathrm{Fe}^{2+}$ in the photo-Fenton process causes the brown turbidity to be darker, which prevents the observation of the UV light that is needed for photolysis and recombination of $\mathrm{OH}$ radicals. In this case, $\mathrm{Fe}^{2+}$ reacts with $\mathrm{OH}$ radicals as a scavenger [55].

\section{The Effect of Reaction Time}

As illustrated in Figs 2(a, b, c, d) and 3(a, b, c, d), with increasing reaction time the percentage of degradation

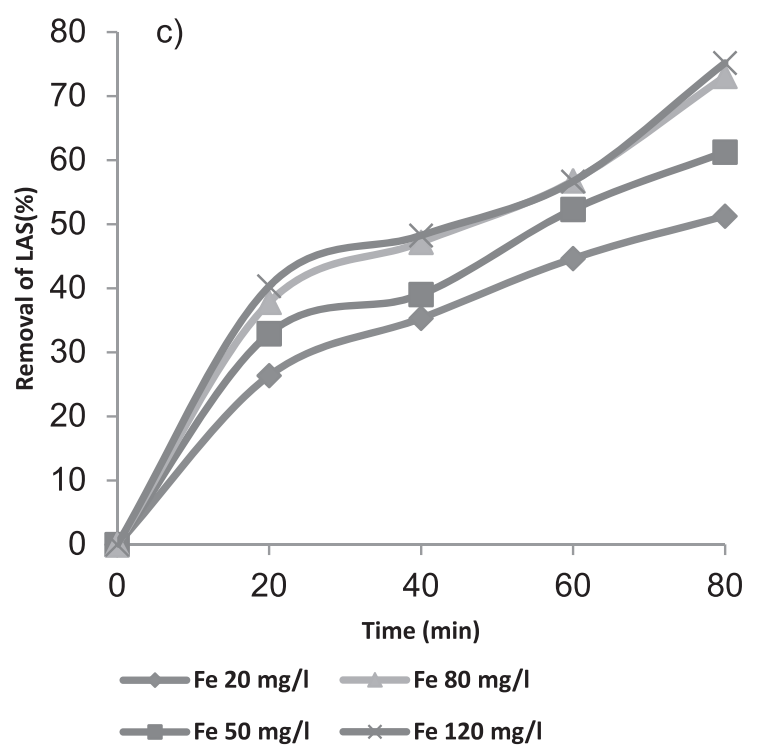

Fig. 3c). Effect of reaction time on photo-Fenton process for the degradation LAS (conditions: initial LAS degradation, $200 \mathrm{mgL}^{-1}$; initial $\mathrm{PH}, 3 ; \mathrm{H}_{2} \mathrm{O}_{2}$ concentration; $600 \mathrm{mgL}^{-1}$ ).

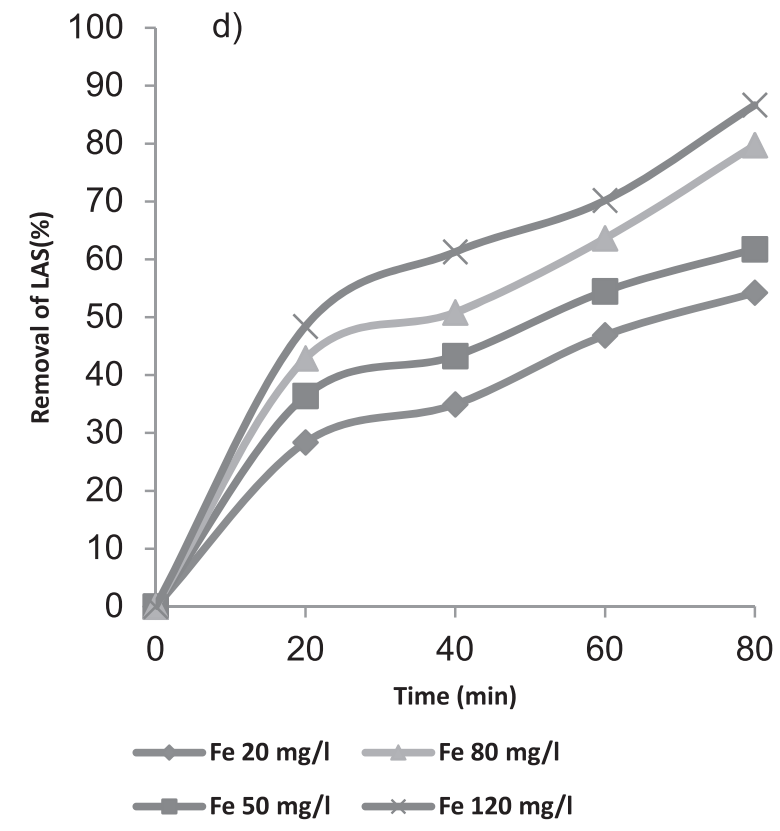

Fig. 3d). Effect of reaction time on photo-Fenton process for the degradation LAS (conditions: initial LAS degradation, $200 \mathrm{mgL}^{-1}$; initial $\mathrm{PH}, 3 ; \mathrm{H}_{2} \mathrm{O}_{2}$ concentration; 800 $\mathrm{mLL}^{-1}$ ). and removal of LAS in the Fenton process mounts and the removal rate at $20,40,60$, and 80 minutes reaches 38.2 , $44.72,55.83$, and $69.38 \%$, respectively, but in photoFenton to $48.41,61.28,70.17$, and $86.66 \%$, respectively.

In fact, photo-Fenton process efficiency is observed more than for Fenton, which is due to UV radiation accelerating the formation of hydroxyl $(\mathrm{OH})$ radicals as well as faster removal of LAS.

Also, our study found that the total squared errors for the time factor by themselves are 29,149, whereas the explained squared errors by other factors and time factor are too small. So the time factor has the most effect regarding contract time with $\mathrm{H}_{2} \mathrm{O}_{2}$ concentration of $(2,148.28)$, then the most effect relates to contract time with $\mathrm{Fe}^{2+}$ concentration $(1,259)$. Of course the contract effects of all factors mentioned relate to surfactant removal, which was significantly meaningful except the interaction of four factor effects (Time*method* $\mathrm{H}_{2} \mathrm{O}_{2}$ dose $* \mathrm{Fe}^{2+}$ dose $)(\mathrm{P}$ value $<0.05)$.

\section{Conclusions}

This study confirms that both Fenton and photoFenton processes are efficient methods for the treatment of wastewaters with high anionic surfactant concentration prior to discharge to the environment. Our study also reveals that LAS removal efficiency for photo-Fenton is higher than for the Fenton process and the anionic surfactant removal in both methods are highly dependent on reaction time. The correlation between anionic surfactant removal and $\mathrm{H}_{2} \mathrm{O}_{2}$ and $\mathrm{Fe}^{2+}$ concentration was less significant.

\section{Acknowledgements}

This paper is extracted from the results of research project No. 9132, which was conducted at Kashan University of Medical Sciences. The authors are grateful to the deputy of research of Kashan University of Medical Sciences for financial support.

\section{References}

1. BRAGA, J.K., MOTTERAN, F., SILVA, E. L., Varesche M. B. A., Evaluation of bacterial community from anaerobic fluidized bed reactor for the removal of linear alkylbenzene sulfonate from laundry wastewater by 454 -pyrosequence. Ecological Engineering 82, 231, 2015.

2. BELTRÁN-HEREDIA J., SÁNCHEZ-MARTÍN J., Removal of sodium lauryl sulphate by coagulation/flocculation with Moringa oleifera seed extract. Journal of Hazardous Materials 164 (2-3), 713, 2009.

3. OLIVER-RODRÍGUEZ B., ZAFRA-GÓMEZ A., REIS M.S., DUARTE B.P., VERGE C., DE FERRER J.A., PÉREZ-PASCUAL M., VÍLCHEZ J.L., Evaluation of Linear Alkylbenzene Sulfonate (LAS) behaviour in agricultural soil through laboratory continuous studies. Chemosphere 131, 1, 2015. 
4. ALOUI F., KCHAOU S., SAYADI S., Physicochemical treatments of anionic surfactants wastewater: Effect on aerobic biodegradability. Journal of Hazardous Materials 164 (1), 353, 2009.

5. YÜKSEL E., ŞENGIL İ.A., ÖZACAR M. The removal of sodium dodecyl sulfate in synthetic wastewater by peroxielectrocoagulation method. Chemical Engineering Journal 152 (2-3), 347, 2009.

6. HEIBATI B., GHOOCHANI M., ALBADARIN A.B., MESDAGHINIA A., HAMDY MAKHLOUF A.S., ASIF M., MAITY A., TYAGI I., AGARWAL S., GUPTA V.K., Removal of linear alkyl benzene sulfonate from aqueous solutions by functionalized multi-walled carbon nanotubes. Journal of Molecular Liquids 213, 339, 2016.

7. AYRANCI E., DUMAN O., Removal of anionic surfactants from aqueous solutions by adsorption onto high area activated carbon cloth studied by in situ UV spectroscopy. Journal of Hazardous Materials 148 (1-2), 75, 2007.

8. ARIAPAD A., ZANJANCHI M.A., ARVAND M., Efficient removal of anionic surfactant using partial templatecontaining MCM-41. Desalination 284 (0), 142, 2012.

9. OLIVER-RODRÍGUEZ B., ZAFRA-GÓMEZ A., REIS M.S., DUARTE B.P.M., VERGE C., DE FERRER J.A., PÉREZ-PASCUAL M., VÍLCHEZ J.L. Wide-range and accurate modeling of linear alkylbenzene sulfonate (LAS) adsorption/desorption on agricultural soil. Chemosphere 138,148, 2015.

10. GAVALA H.N., AHRING B.K., Inhibition of the anaerobic digestion process by linear alkylbenzene sulfonates. Biodegradation 13 (3), 201. 2002.

11. MÉNDEZ-DÍAZ J., SÁNCHEZ-POLO M., RIVERAUTRILLA J., CANONICA S., VON GUNTEN U. Advanced oxidation of the surfactant SDBS by means of hydroxyl and sulphate radicals. Chemical Engineering Journal 163 (3), 300, 2010.

12. MEHRVAR M., TABRIZI G.B., ABDEL-JABBAR N. Effects of pilot-plant photochemical pre-treatment (UV/ $\mathrm{H}_{2} \mathrm{O}_{2}$ ) on the biodegradability of aqueous linear alkylbenzene sulfonate (LAS). International Journal of Photoenergy 7 (4), $169,2005$.

13. KOPARAL A.S., ÖNDER E., ÖÜTVEREN Ü.B. Removal of linear alkylbenzene sulfonate from a model solution by continuous electrochemical oxidation. Desalination 197 (1-3), 262, 2006.

14. MUNGRAY A.K., KUMAR P., Fate of linear alkylbenzene sulfonates in the environment: A review. International Biodeterioration \& Biodegradation 63 (8), 981, 2009.

15. CANTARERO S., PRIETO C.A., LÓPEZ I., Occurrence of high-tonnage anionic surfactants in Spanish sewage sludge. Journal of Environmental Management 95, Supplement (0), S149-, 2012.

16. ABOULHASSAN M.A., SOUAB S., YAACOUBI A., BAUDU M. Removal of surfactant from industrial wastewaters by coagulation flocculation process. Internation Journal of Environmental Science and Technology 3 (4), 327, 2006.

17. GHANBARIAN M., NABIZADEH R., MAHVI A.H., NASSERI S., NADDAFI K. Photocatalytic degradation of linear alkyl benzene solfunate from aqueous solution by $\mathrm{TiO}_{2}$ nanoparticles. Iranian Journal of Environmental Health Science \& Engineering 8 (4), 309, 2011.

18. MUNGRAY A.K., KUMAR P. Occurrence of anionic surfactants in treated sewage: Risk assessment to aquatic environment. Journal of Hazardous Materials 160 (2-3), $362,2008$.
19. BRAGA J.K., MOTTERAN F., MACEDO T.Z., SAKAMOTO I.K., OKADA D.Y., SILVA E.L., VARESCHE M.B.A. Biodegradation of linear alkylbenzene sulfonate in commercial laundry wastewater by an anaerobic fluidized bed reactor. Journal of Environmental Science and Health, Part A. 50 (9), 946, 2015.

20. LOUHICHI B., AHMADI M.F., BENSALAH N., GADRI A., RODRIGO M.A. Electrochemical degradation of an anionic surfactant on boron-doped diamond anodes. Journal of Hazardous Materials 158 (2-3), 430, 2008.

21. DEHGHANI M.H., NAJAFPOOR A.A., AZAM K. Using sonochemical reactor for degradation of LAS from effluent of wastewater treatment plant. Desalination 250 (1),. 82, 2010.

22. NCIBI M.C., GASPARD S., SILLANP ÄÄ, M. Assynthesized multi-walled carbon nanotubes for the removal of ionic and non-ionic surfactants. Journal of Hazardous Materials 286, 195, 2015.

23. PANIZZA M., BARBUCCI A., DELUCCHI M., CARPANESE M.P., GIULIANO A., CATALDOHERNÁNDEZ M., CERISOLA G. Electro-Fenton degradation of anionic surfactants. Separation and Purification Technology 118, 394, 2013.

24. MOLLAEI J., MORTAZAVI S.B., JAFARI A.J. Applying moving bed biofilm reactor for removing linear alkylbenzene sulfonate using synthetic media. Iranian Journal of Health, Safety and Environment 2 (1), 204, 2015.

25. LIAO Q., SUN J., GAO L., Degradation of phenol by heterogeneous Fenton reaction using multi-walled carbon nanotube supported $\mathrm{Fe}_{2} \mathrm{O}_{3}$ catalysts. Colloids and Surfaces A: Physicochemical and Engineering Aspects 345 (1-3), 95, 2009.

26. CARLOS L., FABBRI D., CAPPARELLI A.L., PREVOT A.B., PRAMAURO E., GARCÍA EINSCHLAG F.S. Intermediate distributions and primary yields of phenolic products in nitrobenzene degradation by Fenton's reagent. Chemosphere 72 (6), 952, 2008.

27. POYATOS J.M., MUÑIO M.M., ALMECIJA M.C., TORRES J.C., HONTORIA E., OSORIO F. Advanced oxidation processes for wastewater treatment state of the art. Water, Air \& Soil Pollution 205 (1-4), 187, 2010.

28. GHADERPOORI M., DEHGHANI M.H., Investigating the removal of linear alkyl benzene sulfonate from aqueous solution by ultraviolet irradiation and hydrogen peroxide process. Desalination and Water Treatment 1-5, 2015.

29. NÚÑEZ L., GARCÍA-HORTAL J.A. TORRADES F. Study of kinetic parameters related to the decolourization and mineralization of reactive dyes from textile dyeing using Fenton and photo-Fenton processes. Dyes and Pigments $\mathbf{7 5}$ (3), 647, 2007.

30. WANG X.-J., SONG Y., MAI J.-S. Combined Fenton oxidation and aerobic biological processes for treating a surfactant wastewater containing abundant sulfate. Journal of Hazardous Materials 160 (2), 344, 2008.

31. MANOUSAKI E., PSILLAKIS E., KALOGERAKIS N., MANTZAVINOS D. Degradation of sodium dodecylbenzene sulfonate in water by ultrasonic irradiation. Water research 38 (17), 3751, 2004.

32. RIVERA-UTRILLA J., MÉNDEZ-DÍAZ J., SÁNCHEZPOLO M., FERRO-GARCÍAM.A. BAUTISTA-TOLEDOI. Removal of the surfactant sodium dodecylbenzenesulphonate from water by simultaneous use of ozone and powdered activated carbon: Comparison with systems based on $\mathrm{O}_{3}$ and $\mathrm{O}_{3} / \mathrm{H}_{2} \mathrm{O}_{2}$. Water research $40(8), 1717,2006$.

33. DONG Y., WANG T., WAN X., HE D. Washing and Dyeing 
Wastewater Treatment by Combined Nano Flocculation and Photocatalysis Processes. Journal of Geoscience and Environment Protection 3 (2), 66, 2015.

34. CUZZOLAA., BERNINI M., SALVADORI P. A preliminary study on iron species as heterogeneous catalysts for the degradation of linear alkylbenzene sulphonic acids by $\mathrm{H}_{2} \mathrm{O}_{2}$. Applied Catalysis B: Environmental 36 (3), 231, 2002.

35. SANZ J., LOMBRAÑA J.I., MA DE LUIS A., VARONA F. UV/ $\mathrm{H}_{2} \mathrm{O}_{2}$ chemical oxidation for high loaded effluents: A degradation kinetic study of LAS surfactant wastewaters. Environmental technology 24 (7), 903, 2003.

36. ZHU S.-N., WANG C., YIP A.C.K., DANIEL C.W. Highly effective degradation of sodium dodecylbenzene sulphonate and synthetic greywater by Fenton-like reaction over zerovalent iron-based catalyst. Environmental technology 36 (11), 1423, 2015

37. FATHI G.,YENGEJEH R.J., KOHGERDI E., JANMOHAMMADI F. Bioremediation of anionic surfactants in hospital wastewater. Case study: Shahid Beheshti Hospital in Abadan City, Iran. AES Bioflux 8 (1), 50. 2016.

38. CAI M., SU J., ZHU Y., WEI X., JIN M., ZHANG H., DONG C., WEI Z. Decolorization of azo dyes Orange G using hydrodynamic cavitation coupled with heterogeneous Fenton process. Ultrasonics sonochemistry 28, 302, 2016.

39. AMOR C., TORRES-SOCÍAS E.D., PERES J.A., MALDONADO M.I., OLLER I., MALATO S., LUCAS M.S. Mature landfill leachate treatment by coagulation/ flocculation combined with Fenton and solar photo-Fenton processes. Journal of hazardous materials 286, 261, 2015.

40. MUNTER R. Advanced oxidation processes-current status and prospects. Proc. Estonian Acad. Sci. Chem. 50 (2), 59, 2001.

41. TARR M.A., Chemical degradation methods for wastes and pollutants: environmental and industrial applications, CRC Press. 2003.

42. ESMAELI R. HASSANI A.H., ESLAMI A., MOGHADAM AHMADI, M., SAFARI A.A. Di-(2-Ethylhexyl) Phthalate oxidative degradation by Fenton process in synthetic and real petrochemical wastewater. Iranian Journal of Environmental Health Science \& Engineering 8 (3), 201, 2011.

43. MOUSAVI S.A.R., MAHVI A.H., NASSERI S., GHAFARI SH., Effect of Fenton process $\left(\mathrm{H}_{2} \mathrm{O}_{2} / \mathrm{Fe}^{2+}\right)$ on removal of linear alkylbenzene sulfonate (LAS) using centeral composite design and response surface methodology. Iranian Journal of Environmental Health Science \& Engineering 8 (2), 111, 2011.
44. ROMERO V., GONZÁLEZ O., BAYARRI B., MARCO P., GIMÉNEZ J., ESPLUGAS S. Degradation of Metoprolol by photo-Fenton: Comparison of different photoreactors performance. Chemical Engineering Journal 283, 639, 2016.

45. HANSSON H., KACZALA F., MARQUES M., HOGLAND W. Photo-Fenton and Fenton Oxidation of Recalcitrant Wastewater from the Wooden Floor Industry. Water Environment Research 7 (6), 491, 2015.

46. BARBUSIŃSKI K., FILIPEK K. Use of Fenton's reagent for removal of pesticides from industrial wastewater. Polish Journal of Environmental Studies 10 (4), 207, 2001.

47. LI A., HE M., DONG N., XU W., PAN T. The feasibility of AOPs and an SBR for treating wastewater from polyurethane manufacturing. Polish Journal of Environmental Studies $\mathbf{2 3}$ (4). 1219, 2014.

48. ABU HASSAN M.A., YUSOF R., SITI H.A.M. Fenton degradation of linear alkylbenzene sulphonates (LAS). Journal of Chemical \&Natural Resources Engineering 2, 22, 2007.

49. ONO E., TOKUMURA M., KAWASE Y. Photo-Fenton degradation of non-ionic surfactant and its mixture with cationic or anionic surfactant. J Environ Sci Health A Tox Hazard Subst Environ Eng. 47 (8), 1087, 2012.

50. WANG X.-J., SONG Y., MAI J.-S. Combined Fenton oxidation and aerobic biological processes for treating a surfactant wastewater containing abundant sulfate. Journal of Hazardous Materials 160 (2-3), 344, 2008.

51. BABUPONNUSAMI A., MUTHUKUMAR K. Advanced oxidation of phenol: A comparison between Fenton, electroFenton, sono-electro-Fenton and photo-electro-Fenton processes. Chemical Engineering Journal 183 (0), 1, 2012.

52. FU F., WANG Q., TANG B. Fenton and Fenton-like reaction followed by hydroxide precipitation in the removal of $\mathrm{Ni}(\mathrm{II})$ from NiEDTA wastewater: A comparative study. Chemical Engineering Journal 155 (3), 769, 2009.

53. PRIMO O., RIVERO M.J., ORTIZ I. Photo-Fenton process as an efficient alternative to the treatment of landfill leachates. Journal of Hazardous Materials 153 (1-2), 834, 2008.

54. LUCAS M.S., PERES J.A. Removal of COD from olive mill wastewater by Fenton's reagent: Kinetic study. Journal of Hazardous Materials 168 (2-3), 1253, 2009.

55. BADAWY M.I., GHALY M.Y., GAD-ALLAH T.A. Advanced oxidation processes for the removal of organophosphorus pesticides from wastewater. Desalination 194 (1-3), 166, 2006. 